\title{
Biodegradable polylactide and thermoplastic starch blends as drug release device - mass transfer study
}

\author{
Karolina Labus ${ }^{1}$, Anna Trusek-Holownia ${ }^{1}$, Damian Semba ${ }^{1}$, Justyna Ostrowska ${ }^{2}$, Piotr Tynski ${ }^{2}$, \\ Jakub Bogusz ${ }^{2}$ \\ ${ }^{1}$ Wroclaw University of Science and Technology, Division of Bioprocess and Biomedical Engineering, Faculty of Chemistry, \\ Poland, Norwida 4/6, 50-373 Wroctaw, Poland \\ ${ }^{2}$ New Chemical Syntheses Institute, Department of Organic Technologies, Aleja Tysiaclecia Państwa Polskiego 13A, 24- \\ 110 Puławy, Poland \\ Corresponding authors: e-mail: karolina.labus@pwredu.pl, justyna.ostrowska@ins.pulawy.pl
}

\begin{abstract}
Four different compositions of polylactide/thermoplastic starch blends (PLA/TPS blends) for application as drug carriers were examined. Initially, using cyanocobalamin $(1.355 \mathrm{kDa})$ as a model compound, the blend with the highest starch content (wt. 60\%) was selected for further research of mass transfer phenomenon. In this case, different concentrations of acetaminophen $(0.151 \mathrm{kDa})$, doxorubicin hydrochloride $(0.580 \mathrm{kDa})$ and cyanocobalamin $(1.355 \mathrm{kDa})$ were used for determination of particular releasing profiles. Besides from the comparative analysis of obtained results, the values of the overall mass transfer coefficient $(\mathrm{K})$ were calculated for each of tested drug molecules. Depending on the size and properties of used compound, determined values of the coefficient range from $10^{-11}$ to $10^{-13} \mathrm{~m} / \mathrm{s}$. Based on these outcomes, it could be stated that PLA/TPS blend selected in preliminary research, seems to be preferred material for fabrication of long-term drug delivery systems, which could be successfully applied for example in anti-cancer therapy.
\end{abstract}

Keywords: polylactide/thermoplastic starch (PLA/TPS) blends, permeability, local drug release, overall mass transport coefficient.

\section{INTRODUCTION}

Biodegradable polymers represent diverse group of eligible materials (e.g. poly(lactic acid) (PLA), poly(glycolic acid) (PGA), poly( $\varepsilon$-caprolactone) (PCL), poly(L-glutamic acid) (PLG), poly(L-lysine) (PLL), polyphosphoesters (PPEs), chitosan, starch, gelatin and others $)^{1,2}$, which play an increasingly significant role in dynamic biotechnological advancements. Thanks to their unique degradability and biocompatibility properties, they become materials of interest, used particularly for medical and pharmaceutical technology purposes ${ }^{\mathbf{1}, 2}$. The first medical application of biodegradable polymers dates back to seventies of the last century when poly(glycolic acid), poly(lactic acid) and their copolymers were developed to use as absorbable surgical sutures ${ }^{3,4}$. Since then, biodegradable polymers have been intensively explored and considered as prominent functional materials developed in various medical fields, such as tissue engineering $^{5,6}$, implantology ${ }^{7}$, surgery ${ }^{8,9}$ and drug delivery ${ }^{10,11}$. In particular, due to ability to undergo decomposition inside the body resulting in non-toxic byproducts (e.g. water, carbon dioxide), they are favorable matrices for the fabrication of drug delivery systems ${ }^{12}$.

In regard to environmental law restrictions and sophisticated demands of food, medical and pharmaceutical industries, rapidly growing interest in the use of biodegradable polymers, obtained from renewable resources is observed ${ }^{13-15}$. In this case, ones of the most promising are polylactide ${ }^{16}$ and $\operatorname{starch}^{17}$.

Polylactide (PLA), an aliphatic polyester and biocompatible thermoplastic, is currently one of the widely studied 'green' eco-friendly polymer produced from the renewable raw materials. PLA is considered as one of the most popular biodegradable polymer with the extensive development prospects ${ }^{18,}{ }^{19}$. The presence of the ester bond in the PLA structure determines its high elasticity, which enable its decomposition under different $\mathrm{pH}$ conditions into non-toxic compounds. The total biodegradation of the PLA ranges from six months to two years ${ }^{20}$. In order to improve PLA properties (e.g. stiffness, permeability, crystallinity and thermal stability), it could be proceed blending with various compounds (mono- or polymers) ${ }^{21}$. Due to their ability to fulfill complex requirements, typically including properties such as: biocompatibility, biodegradability, mechanical strength and processability, polylactide homo-, copolymers and blends have become the materials of choice especially in biomedical applications ${ }^{22}$.

Starch, a natural polysaccharide widely occurred in plants (e.g. potato, maize, wheat), is one of the most abundant, cheap and readily available raw material derived from renewable resources. In native form, starch forms granular structure mostly composed of linear amylose and highly branched amylopectin ${ }^{23}$. When subjected to thermal extrusion process in the presence of plasticizers (e.g. glycerol), starch undergo destructurization resulting in homogeneous melt known as thermoplastic starch (TPS) ${ }^{24-26}$. TPS is compatible with the environment. Moreover, due to its biodegradability, low cost and wide availability it is mainly used as a cheap filler for biodegradable polymers ${ }^{27}$. In this field, the preparation, characterization and application of polylactide/thermoplastic starch blends are subjected to dynamically developing research ${ }^{28,29}$.

The main aim of the study was to verify the potential predisposition of different PLA/TPS blends for application as drug carriers. In this case, the molecule diffusion was considered as a drug release strategy ${ }^{30,31}$. 
In preliminary studies, four materials with different PLA:TPS ratio were examined using cyanocobalamin as a model bioactive compound. Next, detailed mass transport studies were made for one selected material with PLA:TPS ratio 2:3 (wt.\%). In this case, acetaminophen $(0.151 \mathrm{kDa})$, doxorubicin hydrochloride $(0.580 \mathrm{kDa})$ and cyanocobalamin $(1.355 \mathrm{kDa})$ were used as model-size drugs molecules and the values of diffusion coefficient for each of them were experimentally estimated.

\section{MATERIAL AND METHODS}

\section{Material}

Polylactide (PLA Ingeo ${ }^{\mathrm{TM}}$ Biopolymer 2003D) in pelleted form was supplied by NatureWorks (USA). Native potato starch (initial moisture content 12-15\%) was obtained from Trzemeszno Sp. z o.o. Potato Industry Company (Poland). Glycerol (99.5\% purity) was purchased from Brenntag (Poland). Rapeseed oil and beeswax were purchased from local producers (Poland). Acetaminophen (molecular weight, $\mathrm{M}=0.151 \mathrm{kDa}$ ), cyanocobalamin (molecular weight, $\mathrm{M}=1.355 \mathrm{kDa}$ ) and methanol were supplied by Sigma Aldrich (Germany). Doxorubicin hydrochloride (molecular weight, $\mathrm{M}=0.580$ $\mathrm{kDa}$ ) was obtained from Fluorochem Ltd (UK). The other reagents, all of analytical grade, were purchased from Avantor Performance Materials (Poland).

\section{Methods}

\section{Preparation of thermoplastic starch (TPS) and PLA/ TPS blends}

Potato starch was dried to 8-9\% moisture content and mixed with or without some processing additives (oil, wax) and glycerol as plasticizer using high speed mixer (Labtech Engineering, Thailand). The amount of oil and wax was 1.0 wt. $\%$ and 0.5 wt. $\%$ on the dry weight basis of starch, respectively. Starch with other additives were processed using co-rotating twin-screw extruder (Labtech Engineering, Thailand) with screw diameter D $=20$ mm with L:D ratio 48:1 using barrel temperature in the range $70^{\circ} \mathrm{C}-140^{\circ} \mathrm{C}$ and at $100 \mathrm{rpm}$ screw speed to obtain thermoplastic starch (TPS) ${ }^{32}$. The extrusion temperature profile for thermoplastic starch plasticized by glycerol from feed section to melting section was $70 / 90 / 120 / 130 / 140 / 140$ $/ 140 / 140 / 135 / 125 / 115 / 110^{\circ} \mathrm{C}$. Threads of thermoplastic materials coming out of extruder die were cooled with air and then granulated. The obtained TPS was used in preparation of blends with PLA in the next step.

The PLA/TPS blends were also prepared in extrusion process using co-rotating twin screw extruder (Labtech Engineering, Thailand) $\left(150^{\circ} \mathrm{C}-175^{\circ} \mathrm{C}, 100 \mathrm{rpm}\right)$. In this case, the ratios of PLA:TPS equal to $1: 1$ and 2:3 with different additives oil, wax were used.

\section{Preparation of PLA/TPS films}

The obtained PLA/TPS blends in granulates form were blown using a single-screw extruder (Labtech Engineering) with screw diameter $\mathrm{D}=20 \mathrm{~mm}(\mathrm{~L}: \mathrm{D}=30: 1)$ connected to blown film unit (LF-250-COEX, Labtech Engineering) with ring-shaped die to prepare biodegradable films. The blown film extrusion process was carried out at temperature range from $155^{\circ} \mathrm{C}$ to $175^{\circ} \mathrm{C}$ and screw speed of $44 \mathrm{rpm}$. The thickness of prepared films was in the range $50-90 \mathrm{~mm}$.

\section{Mechanical properties of PLA/TPS films}

The mechanical properties including tensile strength and elongation at break of the materials were determined using universal testing machine Instron 3340 according to the ISO 527 standard with a crosshead speed of 100 $\mathrm{mm} / \mathrm{min}$ and load cell capacity of $5 \mathrm{kN}$. For this purpose, the blown films were cut into $15 \mathrm{~mm}$ wide strip samples. Thickness of films was determined with thickness gauge in five places along the sample and arithmetic mean was set to determine tensile properties. The values of tensile strength at break $(\sigma)$ and elongation at break $(\varepsilon)$ were determined using 12 individual samples. Then, the arithmetic mean of 10 results was obtained (two extreme results were rejected).

\section{Preliminary studies of PLA/TPS blends transport pro- perties}

Prior to the main studies, PLA/TPS films (50-90 $\mu \mathrm{m})$ were hydrophilized for $24 \mathrm{~h}$ with 70 vol. $\%$ aqueous solution of methanol. In order to verify the permeation properties of tested materials, the cyanocobalamin (1.355 $\mathrm{kDa}$ ) was used as a model bioactive compound. Briefly, the pouches $(30 \times 75 \mathrm{~mm})$ prepared from the PLA/TPS films were filled in with appropriate concentration of cyanocobalamin prepared in 10 vol.\% methanol and tightly closed with plastic clamp. The experiment was initiated by inserting the pouch filled with cyanocobalamin solution into the beaker, containing the receiving medium (10 vol.\% methanol). The releasing of cyanocobalamin was monitored in the receiving solution by spectrophotometric measurements at $361 \mathrm{~nm}$. Standard curve equation: $\mathrm{C}_{\text {cyanocobalamin }}[\mathrm{g} / \mathrm{L}]=0.0690 \cdot \mathrm{Abs}_{361}\left(\mathrm{R}^{2}=0.9992\right)$ was used.

Next, for the selected membranes (2-4), analogous experiment was performed in aqueous solution.

\section{Mass transfer studies through the film barrier composed of PLA and TPS in a $2: 3$ ratio}

Prior to the mass transfer studies, PLA/TPS films (50-90 $\mu \mathrm{m})$ were hydrophilized for $24 \mathrm{~h}$ with 70 vol. $\%$ aqueous solution of methanol. Initially, the general permeability properties of this material were tested using bioactive compounds of different molecular weights ranging from 0.151 to $66 \mathrm{kDa}$ (acetaminophen $-0.151 \mathrm{kDa}$, doxorubicin hydrochloride $-0.580 \mathrm{kDa}$, cyanocobalamin -1.355 $\mathrm{kDa}$, trypsin - 23.8 kDa, bovine serum albumin - 66.0 $\mathrm{kDa}$ ). The experiments were carried out for 15 days in Ringer's solution at ambient temperature.

In order to investigate the mass transfer phenomena across chosen polymeric barrier, three model drugs molecules of different molecular weight (acetaminophen - $0.151 \mathrm{kDa}$, doxorubicin hydrochloride -0.580 $\mathrm{kDa}$, cyanocobalamin $-1.355 \mathrm{kDa}$ ) were used. Briefly, the pouches $(40 \times 80 \mathrm{~mm})$ prepared from the films with PLA:TPS ratio 2:3 (wt.\%) were washed out twice with Ringer's solution and after drying, they were filled with the solution of a model drug at the appropriate concentration and then tightly closed with plastic clamps. Each experiment was started by inserting the pouch with the solution of the model bioactive compound into the beaker containing the receiving medium (Ringer's solution). The 
releasing rate of each tested compound from the PLA/ TPS reservoir was monitored by measuring changes in absorbance (at the specified wavelength) in a receiving solution. Consecutively, releasing of acetaminophen was monitored at $240 \mathrm{~nm}$ using standard curve $\mathrm{C}_{\text {acetaminophe- }}$ ${ }_{n}[\mathrm{~g} / \mathrm{L}]=0.0149 \cdot \mathrm{Abs}_{240}\left(\mathrm{R}^{2}=0.9996\right)$. The released concentration of doxorubicin was monitored at $476 \mathrm{~nm}$ and calculated from standard $\mathrm{C}_{\text {doxorubicin }}[\mathrm{g} / \mathrm{L}]=0.0309 \cdot \mathrm{Abs}_{476}$ $\left(\mathrm{R}^{2}=0.9993\right)$. In case of cyanocobalamin, the standard curve $\mathrm{C}_{\text {cyanocobalamin }}[\mathrm{g} / \mathrm{L}]=0.0690 \cdot \mathrm{Abs}_{361}\left(\mathrm{R}^{2}=0.9992\right)$ determined at $361 \mathrm{~nm}$ was used.

The overall mass transfer coefficient was determined using equation (1) with the assumption of the equal concentration inside a carrier ${ }^{33}$ :

$K=\frac{1}{1+\frac{V_{c a r}}{V_{\text {rec }}}} \cdot \frac{V_{c a r}}{A \cdot t} \cdot \ln \frac{C_{\text {car }, t=0}}{C_{\text {car }, t} \cdot\left(1+\frac{V_{c a r}}{V_{\text {rec }}}\right)+C_{c a r, t=0} \cdot \frac{V_{c a r}}{V_{\text {rec }}}}$

Where:

A - interphase area (taken as a total carrier area; without porosity considering) $\left[\mathrm{m}^{2}\right]$;

$\mathrm{C}_{\mathrm{car}}$ - concentration of compound inside the carrier $\left[\mathrm{kg} / \mathrm{m}^{3}\right]$;

$\mathrm{K}$ - overall mass transfer coefficient $[\mathrm{m} / \mathrm{s}]$

$\mathrm{t}$ - time [s];

$\mathrm{V}_{\text {car }}$ - volume inside the carrier $\left[\mathrm{m}^{3}\right]$;

$\mathrm{V}_{\text {rec }}-$ volume of receiving phase $\left[\mathrm{m}^{3}\right]$.

\section{RESULTS AND DISCUSSION}

\section{Preliminary research}

The blends of polylactide (PLA) and thermoplastic starch (TPS) in form of thin film were prepared in singlescrew extrusion process. The PLA/TPS materials used in present study were manufactured in the Department of Organic Technologies of New Chemical Syntheses Institute (Puławy, Poland) and details of their production procedure are protected by rigorous technological confidentiality requirements. The composition of obtained PLA/TPS materials and their mechanical properties are shown in Table 1.

The values of tensile strength at break and elongation at break of commercial polylactide are $70.1 \mathrm{MPa}$ and $9.6 \%$, respectively. The TPS addition into the PLA matrix causes an increase of $\varepsilon$ value by over $200 \%$ compared to pure polylactide and leads to obtain flexible films. On the other hand, the tensile strength of polylactide was decreased after TPS addition. The cause is low tensile properties of thermoplastic starch - typically below $6 \mathrm{MPa}$ in tensile strength ${ }^{34}$. Furthermore, it is well known that hydrophilic starch and hydrophobic polylactide more common forms incompatible blends than compatible.
The incompatibility results in deterioration of blends mechanical properties. The incorporation of wax improved strength at break (38.7 MPa) and decrease elongation at break (4.6\%) of PLA/TPS film compared to other samples. These results suggest that the movements of the blend molecules restricted after wax incorporation into the polymer matrix. Moreover low elongation at break value of sample (1) suggest that is quite brittle, thus low content of wax could lead to antiplasticization effects. The interactions between starch and wax molecules were not observed in infrared spectroscopy. The FTIR spectra

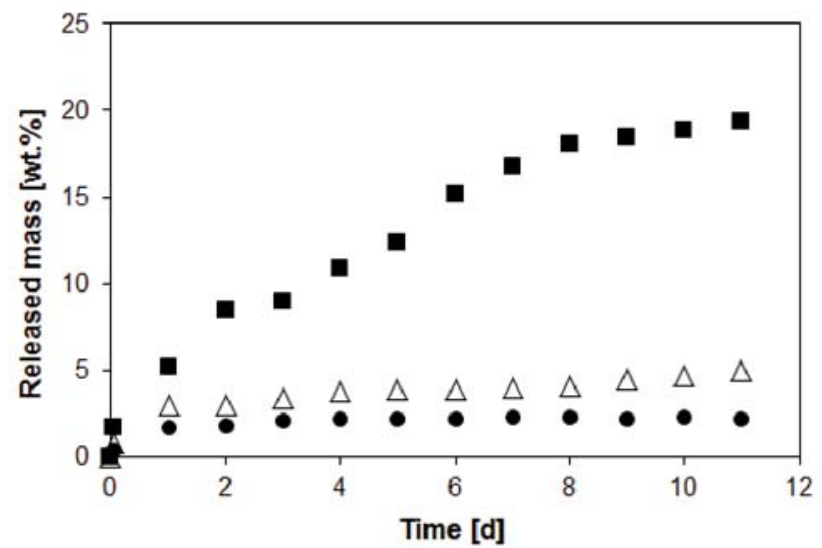

Figure 1. The percent of released mass of cyanocobalamin from containers made of PLA/TPS based materials with different compositions - blend $2(\bullet), 3(\square)$ and $4(\Delta)$; initial concentration of cyanocobalamin 0.96 $\mathrm{g} / \mathrm{L}$, ambient temperature, distilled water as receiver solution

of thermoplastic starch plasticized by glycerol or mixture of glycerol with additives are analogous, therefore the spectra presentation was omitted.

In order to verify the permeation properties of the tested materials, the preliminary experiments were carried out using cyanocobalamin $(1.355 \mathrm{kDa})$ as a model compound and $10 \%$ methanol as solution (the permeability increases with an alcohol contain). The results of these experiments are depicted in Table 1. Due to these data, materials 2, 3 and 4 were chosen for the studies in water (Fig. 1).

The mass transport of the model compound in water through PLA/TPS films 2 and 4 was alarmingly too slow. Therefore, in aspect of long-term drug therapy, the most suitable values of released cyanocobalamin were obtained for blend 3 produced at the PLA:TPS ratio 2:3 and this material was subjected to further research.

Table 1. Formulation, mechanical properties and the percent of released mass of cyanocobalamin from containers made of PLA/ TPS blends with different composition; initial concentration of cyanocobalamin $1.63 \mathrm{~g} / \mathrm{L}$, ambient temperature, 10 vol.\% methanol in water as receiver solution

\begin{tabular}{|c|c|c|c|c|c|c|c|c|c|}
\hline \multirow{2}{*}{ No. } & \multirow{2}{*}{$\begin{array}{l}\text { PLA }^{a} \\
\text { [wt.\%] }\end{array}$} & \multirow{2}{*}{$\begin{array}{l}\text { TPS }^{b} \\
\text { [wt. \%] }\end{array}$} & \multirow{2}{*}{$\begin{array}{l}\text { Additives } \\
{[-]}\end{array}$} & \multirow{2}{*}{$\begin{array}{c}\sigma^{\mathrm{c}} \\
{[\mathrm{MPa}]}\end{array}$} & \multirow{2}{*}{$\begin{array}{c}E^{d} \\
{[\mathrm{MPa}]}\end{array}$} & \multirow{2}{*}{$\begin{array}{l}\varepsilon^{e} \\
{[\%]}\end{array}$} & \multicolumn{3}{|c|}{$\begin{array}{l}\text { Released cyanocobalamin } \\
\text { [wt.\%] }\end{array}$} \\
\hline & & & & & & & $3 \mathrm{~h}$ & $23 \mathrm{~h}$ & $72 \mathrm{~h}$ \\
\hline 1 & 50 & 50 & Wax & 38.7 & 1810 & 4.6 & 0.26 & 0.58 & 0.72 \\
\hline 2 & 50 & 50 & Oil & 26.5 & 1345 & 245.0 & 1.33 & 3.35 & 3.31 \\
\hline 3 & 40 & 60 & - & 23.2 & 1183 & 203.9 & 3.71 & 7.12 & 7.70 \\
\hline 4 & 50 & 50 & - & 30.5 & 1473 & 267.4 & 0.65 & 0.83 & 1.01 \\
\hline
\end{tabular}

where: ${ }^{a}$ polylactide, ${ }^{b}$ thermoplastic starch, ${ }^{c}$ tensile strength at break, ${ }^{d}$ modulus of elasticity, ${ }^{\mathrm{e}}$ elongation at break. 


\section{Mass transfer studies of model drugs}

The PLA/TPS blend selected in preliminary research was subjected to more detailed studies. Initially, the general permeability properties of this material were tested using bioactive compounds of different molecular weight ranging from 0.151 to $66 \mathrm{kDa}$. The experiments were carried out in ambient temperature for 15 days. It was observed that the blend consisting of PLA and TPS in a ratio of $2: 3 \mathrm{wt} . \%$ was well permeable to molecules below $2.0 \mathrm{kDa}$ (the typical drug molecules sizes) and completely impermeable to compounds of weight above $20 \mathrm{kDa}$ (the value corresponding to immune response proteins). Due to obtained results three model drug molecules (acetaminophen - $0.151 \mathrm{kDa}$, doxorubicin hydrochloride $-0.580 \mathrm{kDa}$ and cyanocobalamin -1.355 $\mathrm{kDa}$ ) were chosen for further studies of mass transfer phenomena.

Considering biomedical applications of the PLA/TPS materials as drug carriers, the precise determination of the individual release profiles and detailed descriptions of those processes are crucial. Therefore, in order to determine the release progress and calculation of the overall mass transfer coefficients, each of the model compounds was tested at four different concentrations. Acetaminophen and doxorubicin were used in a range of about $0.02-0.28 \mathrm{~g} / \mathrm{L}$, whereas in case of cyanocobalamin, thanks to its good solubility, higher concentrations $(\sim 0.28-2.30 \mathrm{~g} / \mathrm{L})$ were tested. All release processes were performed under conditions simulating the physiological environment of the human body fluids (Ringer's solution, $37^{\circ} \mathrm{C}$ ). The results are depicted in Figure 2.

As expected, it was noticed that release progress proceeded slowest for the largest model molecule tested in this study (Fig. 2c, cyanocobalamin). By comparing the results obtained after $24 \mathrm{~h}$ of release process for similar initial concentrations of applied drugs (Fig. 2 a (०),b (○) $c(\Delta))$ it was observed that in case of acetaminophen and doxorubicin the amount of released mass was respectively over sixfold and twice higher than for cyanocobalamin. Subsequently, for each tested compound, the overall mass transfer coefficient was determined (Table 2).

Obtained values of $\mathrm{K}$ vary between $10^{-11}$ and $10^{-13}$ $\mathrm{m} / \mathrm{s}$, what properly correspond to weeks long therapy time ${ }^{31,35}$. The result for cyanocobalamin entrapped in PLA/TPS film $\left(\mathrm{K}=3.996 \cdot 10^{-13} \mathrm{~m} / \mathrm{s}\right)$ could be directly compared with those obtained in previous work ${ }^{31}$. The overall mass transfer coefficients determined for cyanocobalamin immobilized in alginate capsules covered with polyethersulfone, polysulfone or cellulose acetate semi-permeable membrane was equal to $3.611 \cdot 10^{-9}$, $1.600 \cdot 10^{-9}$ and $9.028 \cdot 10^{-8}$ respectively ${ }^{31}$. In this case, mass transfer across PLA/TPS film barrier is $4-5$ orders

Table 2. The overall mass transfer coefficients determined for the model bioactive compounds with different molecular weight

\begin{tabular}{|l|c|c|c|}
\hline Model compound & $\begin{array}{c}\mathrm{M}_{\mathrm{w}}{ }^{\mathrm{a}} \\
{[\mathrm{kDa}]}\end{array}$ & $\begin{array}{c}\mathrm{K}^{\mathrm{b}} \\
{[\mathrm{m} / \mathrm{s}]}\end{array}$ & $\begin{array}{c}\mathrm{RE}^{\mathrm{c}} \\
{[\%]}\end{array}$ \\
\hline Acetaminophen & 0.151 & $1.239 \cdot 10^{-11} \pm 0.252 \cdot 10^{-11}$ & 6.54 \\
\hline Doxorubicin & 0.544 & $0.492 \cdot 10^{-11} \pm 0.058 \cdot 10^{-11}$ & 8.92 \\
\hline Cyanocobalamin & 1.335 & $0.040 \cdot 10^{-11} \pm 0.005 \cdot 10^{-11}$ & 7.11 \\
\hline
\end{tabular}

where: ${ }^{a}$ molecular weight, ${ }^{b}$ overall mass transfer coefficient calculated as an average from 16-20 independent experimental points, ${ }^{c}$ - relative error
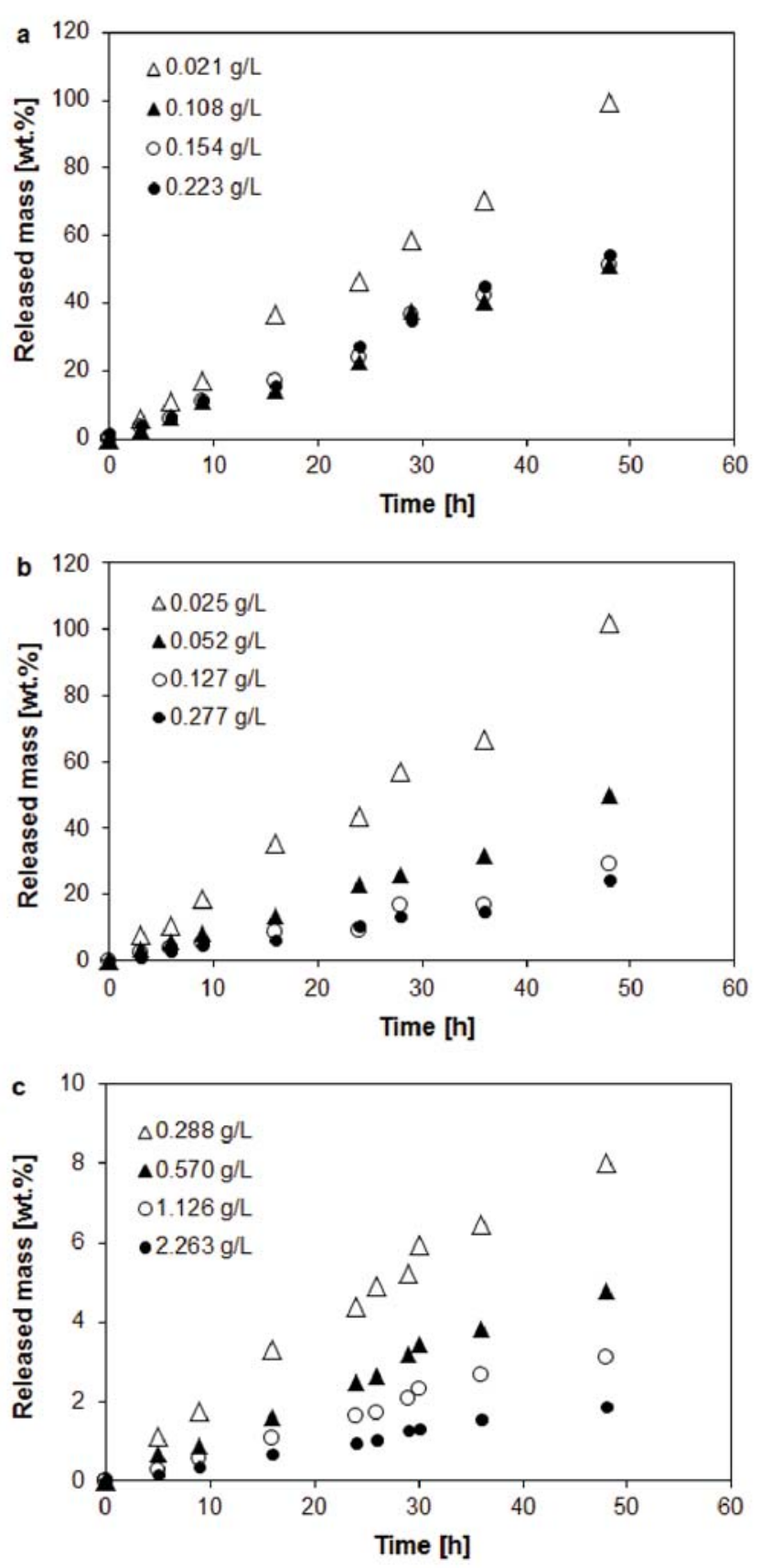

Figure 2. The percentage of a mass released from reservoirs made of PLA/TPS blends in 2:3 ratio determined for different initial concentrations of a given model bioactive compound; acetaminophen (a), doxorubicin hydrochloride (b) and cyanocobalamin (c)

of magnitude lower. It's an important advantage in a long-term medical therapy.

\section{CONCLUSION}

Both polylactide (PLA) and thermoplastic starch (TPS) from chemical point of view are characterized by good biocompatibility and biodegradability, which makes them a subject of great interest for pharmaceutical and medical applications. The main aim of the study was to verify potential predisposition of different PLA/TPS blends for application as drug carriers. In this case, after a preliminary examination of permeable properties, a film composed of PLA and TPS in a 2:3 ratio was selected from the group of four materials varied in the content of particular building blocks. Subsequently, this mate- 
rial was subjected to detailed research of mass transfer phenomenon using three model bioactive compounds varied in molecular weight $(0.151-1.355 \mathrm{kDa})$. Obtained values of the overall mass transfer coefficient are in the range from $10^{-11}$ to $10^{-13} \mathrm{~m} / \mathrm{s}$ (depending on the size and properties of used compound).

Summarizing experimental research performed in current study, it could be stated that the blend composed of PLA and TPS in 2:3 wt.\% ratio, seems to be promising material for the fabrication of efficient prolonged drug release systems, which could be successfully applied for example in anti-cancer therapy.

\section{ACKNOWLEDGMENTS}

This work was performed within the project of National Science Centre in Poland No. 2013/11/B/ST8/03672.

\section{LITERATURE CITED}

1. Tian, H., Tang, Z., Zhuang, X., Chen, X. \& Jing, X. (2012). Biodegradable synthetic polymers: Preparation, functionalization and biomedical application. Prog. Polym. Sci. 37(2), 237-280. DOI: 10.1016/j.progpolymsci.2011.06.004.

2. Ulery, B.D., Nair, L.S. \& Laurencin, C.T. (2011). Biomedical Applications of Biodegradable Polymers. Polym. Sci. B Polym. Phys. 49(12), 832-864. DOI: 10.1002/polb.22259.

3. Kulkarni, R.K., Moore, E.G., Hegyeli, A.F. \& Leonard, F. (1971). Biodegradable poly(lactic acid) polymers. J. Biomed. Mater. Res. 5(3), 169-181. DOI: 10.1002/jbm.820050305.

4. Gilding, D.K. \& Reed, A.M. (1979). Biodegradable polymers for use in surgery-polyglycolic/poly(lactic acid) homo- and copolymers: 1 . Polymer 20(12), 1459-1464. DOI: 10.1016/0032-3861(79)90009-0.

5. Martina, M. \& Hutmacher, D.W. (2007). Biodegradable polymers applied in tissue engineering research: a review. Polym. Int. 56, 145-157. DOI: 10.1002/pi.2108.

6. Asghari, F., Samiei, M., Adibkia, K., Akbarzadeh, A. \& Davaran, S. (2017). Biodegradable and biocompatible polymers for tissue engineering application: a review. Artif. Cells Nanomed. Biotechnol. 45(2), 185-192. DOI: 10.3109/21691401.2016.1146731.

7. Adeosun, S.O., Lawal, G.I. \& Gbenebor, O.G. (2014). Characteristics of Biodegradable Implants. J. Mineral. Mater. Charact. Eng. 2, 88-106. DOI: 10.4236/jmmce.2014.22013.

8. Friedman, J.A., Windebank, A.J., Moore, M.J., Spinner, R.J., Currier, B.L. \& Yaszemski, M.J. (2002). Biodegradable Polymer Grafts for Surgical Repair of the Injured Spinal Cord. Neurosurgery 51(3), 742-752. DOI: 10.1227/00006123200209000-00024.

9. Behrens, A.M., Lee, N.G., Casey, B.J., Sinivasan, P., Sikorski, M.J., Daristotle, J.L., Sandler, A.D. \& Kofinas, P. (2015). Biodegradable-Polymer-Blend-Based Surgical Sealant with Body-Temperature-Mediated Adhesion. Adv. Mater. 27, 8056-8061. DOI: 10.1002/adma.201503691.

10. Gavasane, A.J. \& Pawar, H.A. (2014). Synthetic biodegradable polymers used in controlled drug delivery system: an overview. Clin. Pharmacol. Biopharm. 3(2):121, 1-7. DOI: 10.4172/2167-065X.1000121.

11. Kamaly, N., Yameen, B., Wu, J. \& Farokhzad, O.C. (2016). Degradable controlled-release polymers and nanoparticles: mechanisms of controlling drug release. Chem. Rev. 116, 2602-2663. DOI: 10.1021/acs.chemrev.5b00346.

12. Fredenberg, S., Wahlgren, M., Reslow, M. \& Axelsson, A. (2011). The mechanism of drug release in poly(lactic-coglycolic acid)-based drug delivery systems - a review. Int. J. Pharm. 415, 34-52. DOI: 10.1016/j.ijpharm.2011.05.049.

13. Guilbert, S., Guillaume, C. \& Gontard, N. (2010). New Packaging Materials Based on Renewable Resources: Proper- ties, Applications, and Prospects. In: J. Aguilera, R. Simpson, J. Welti-Chanes, D. Bermudez-Aguirre \& G. Barbosa-Canovas (Eds), Food Engineering Interfaces. Food Enginee. Ser. (pp. 619-630). Springer, New York, NY. DOI: 10.1007/978-1-44197475-4_26.

14. Iwata, T. (2015). Biodegradable and Bio-Based Polymers: Future Prospects of Eco-Friendly Plastics. Angew. Chem. Int. Ed. 54, 3210-3215. DOI: 10.1002/anie.201410770.

15. Zia, K.M., Noreen, A., Zuber, M., Tabasum, S. \& Mujahid, M. (2016). Recent developments and future prospects on bio-based polyesters derived from renewable resources: A review. Int. J. Biol. Macromol. 82, 1028-1040. DOI: 10.1016/j. ijbiomac.2015.10.040.

16. Dorgan, J.R., Lehermeier, H.J., Palade, L.I. \& Cicero, J. (2001). Polylactides: properties and prospects of an environmentally begin plastic from renewable resources. Macromol. Symp. 175, 55-66. DOI: 10.1002/1521-3900(200110)175:1<55::AIDMASY55>3.0.CO;2-K.

17. Kaur, L., Singh, J. \& Liu, Q. (2007). Starch - A Potential Biomaterial for Biomedical Applications. In: M.R. Mozafari (Eds), Nanomaterials and Nanosystems for Biomedical Applications (pp. 83-98). Springer, Dordrecht. DOI: 10.1007/9781-4020-6289-6 5.

18. Jamshidian, M., Tehrany, E. A., Imran, M., Jacquot, M. \& Desobry, S. (2010). Poly-Lactic Acid: Production, Applications, Nanocomposites, and Release Studies. Compr. Rev. Food Sci. Food Saf. 9, 552-571. DOI: 10.1111/j.1541-4337.2010.00126.x.

19. Chen, Y., Geever, L.M., Killion, J.A., Lyons, J.G., Higginbotham, C.L. \& Devine, D.M. (2016). Review of Multifarious Applications of Poly (Lactic Acid). Polym. Plast. Technol. Eng. 55(10), 1057-1075. DOI: 10.1080/03602559.2015.1132465.

20. Pluta, M. (2004). Morphology and properties of polylactide modified by thermal treatment, filling with layered silicates and plasticization. Polymer 45(24), 8239-8251. DOI: 10.1016/j. polymer.2004.09.057.

21. Nagarajan, V., Monhanty, A.K. \& Misra, M. (2016). Perspective on Polylactic Acid (PLA) based Sustainable Materials for Durable Applications: Focus on Toughness and Heat Resistance. ACS Sustainable Chem. Eng. 4, 2899-2916. DOI: 10.1021/acssuschemeng.6b00321.

22. Saini, P., Arora, M. \& Ravi Kumar, M.N.V. (2016). Poly(lactic acid) blends in biomedical applications. Adv. Drug Deliv. Rev. 107, 47-59. DOI: 10.1016/j.addr.2016.06.014.

23. Alcázar-Alay, S.C. \& Meireles, M.A.A. (2015). Physicochemical properties, modifications and applications of starches from different botanical sources. Food Sci. Technol. Campinas 35(2), 215-236. DOI: 10.1590/1678-457X.6749.

24. Liu, H., Xie, F., Yu, L., Chen, L. \& Li, L. (2009). Thermal processing of starch-based polymers. Prog. Polym. Sci. 34(12), 1348-1368. DOI: 10.1016/j.progpolymsci.2009.07.001.

25. Zullo, R. \& Iannace, S. (2009). The effects of different starch sources and plasticizers on film blowing of thermoplastic starch: Correlation among process, elongational properties and macromolecular structure. Carbohyd. Polym. 77(2), 376-383. DOI: 10.1016/j.carbpol.2009.01.007.

26. Nafchi, A.A., Moradpour, M., Saeidi, M. \& Alias, A.K. (2013). Thermoplastic starches: properties, challenges and prospects. Starch 65, 61-72. DOI: 10.1002/star.201200201.

27. Kaseem, M., Hamad, K. \& Deri, F. (2012). Thermoplastic starch blends: a review of recent works. Polym. Sci. A 54(2), 165-176. DOI: 10.1134/S0965545X1202006X.

28. Huneault, M.A. \& Li, H. (2007). Morphology and properties of compatibilized polylactide/thermoplastic starch blends. Polym. 48(1), 270-280. DOI: 10.1016/j.polymer.2006.11.023.

29. Müller, C.M.O., Pires, A.T.N. \& Yamashita, F. (2012). Characterization of Thermoplastic Starch/Poly(Lactic Acid) Blends Obtained by Extrusion and Thermopressing. J. Braz. Chem. Soc. 23(3), 426-434. DOI: 10.1590/S010350532012000300008 . 
30. Siepmann, J. \& Siepmann, F. (2012). Modeling of diffusion controlled drug delivery. J. Control. Release 161(2), 351-362. DOI: 10.1016/j.jconrel.2011.10.006.

31. Trusek-Holownia, A. \& Jaworska, P. (2015). Polymeric drug carriers - control of the daily dose and therapy duration. Bioc. Biomed. Eng. 35(3), 192-197. DOI: 10.1016/j. bbe.2014.11.001.

32. Ostrowska, J., Kozioł, M., Bogusz, J., Sadurski, W. \& Tyński, P. (2017). Biodegradable polymer composition on the basis of thermoplastic starch. Polish Patent Application P. 421850.

33. Trusek-Holownia, A. (2003). A membrane phase contactor for enzymatic synthesis of ZAlaPheOMe, the precursor of bitter dipeptide. Biochem. Eng. J. 16(10), 69-77. DOI: 10.1016/ S1369-703X(03)00143-8.

34. Huang, M., Yu, J. \& Ma, X. (2005). Ethanolamine as a novel plasticizer for thermoplastic starch. Polym. Degrad. Stabil. 90(3), 501-507. DOI: 10.1016/j.polymdegradstab.2005.04.005.

35. Floyd, J.A., Galperin, A. \& Ratner, B.D. (2015). Drug encapsulated polymeric microspheres for intracranial tumor therapy: A review of the literature. Adv. Drug Deliv. Rev. 91, 23-37. DOI: 10.1016/j.addr.2015.04.008. 